\title{
A Method for Measuring Moisture Content in Landfills Based on PGNAA Technique
}

\section{LING YongSheng ${ }^{1, a}$, LI KeWei ${ }^{1}$, ZHANG HaoJia ${ }^{1}$, HEI DaQian ${ }^{1}$, SHAN Qing ${ }^{1}$, CHENG Can ${ }^{1}$, JIA WenBao ${ }^{1}$}

\begin{abstract}
${ }^{1}$ Departmeng of Nuclear Science and Engineering, College of Materials Science and Engineering, Nanjing University of Aeronautics and Astronautics, Nanjing 200016, China;
\end{abstract}

alingyongsheng@nuaa.edu.cn

\section{Keywords: PGNAA, moisture content, element detection, MSW}

Abstract. A new method based on PGNAA technique has been proposed for moisture content and elements concentration determination in landfills. Due to the complexity of MSW component, the compounds of polyethylene balls, glass balls and water were selected as the MSW alternatives for research. By changing the proportion of polyethylene and glass ball, water contents of five samples were regulated to $40.522 \%, 47.575 \%, 55.168 \%, 63.369 \%, 72.251 \%$, respectively. Based on a new set-up was developed to validate the method by MCNP simulations and experimental researches. The results show that the counts of hydrogen peak increase with the increase of the moisture content for samples, and good linearity can be figured out between the counts of hydrogen peak.

\section{Introduction}

Sanitary landfill is an irreplaceable technology of municipal solid waste (MSW) treatment with minimum impact on the health of the public and the environment[1]. However, due to lack of land resources and leachate treatment problems, the future of landfill looks uncertain. In spite of this, landfilling is still the most commonly-used method worldwide for disposal of MSW now. To reduce the aftercare period of land, a common strategy to accelerate waste decomposition in landfills is to stimulate biological activity by adding moisture to the waste via recirculation of leachate and addition of supplemental liquids[2-5]. However, exorbitant moisture content in landfills brings about pollution problems due to more leachate and geological instability caused by slope failure. Hence, as the most critical parameter, moisture control should be achieved by using sensors within the landfill. There are toxic and harmful elements exist in landfill, such as chlorine. The source of chlorine mainly comes from inorganic salt, bleached paper, plastic. Among them high concentration of salt can affect the growth and degradation of microorganisms. In recent years, considerable efforts have been devoted to developing set-ups to measure moisture content and element concentration in landfills [6-9].

Among various in situ measurement devices and techniques, the Prompt Gamma Ray Neutron Activation Analysis (PGNAA) technique has been applied for modern elemental and moisture analysis in different industries due to biggish detecting range and multi-element analysis. A method based on prompt gamma-ray neutron activation analysis (PGNAA) was proposed to detector the moisture content and element concentration. After a brief introduction to the PGNAA technique and the constituent in landfills, the materials and methods are puts forward, followed by the results and analyses.

\section{Methodology}

Prompt gamma-ray neutron activation analysis (PGNAA) technology is on the strength of the detection of prompt gamma-rays which emitted following thermal neutron seized reactions in the sample. The energies of the gamma-rays are characteristic, and the number of detected gamma-rays are proportional to the concentration of corresponding isotopes [10]. Therefore, the prompt gamma-rays spectrum that picked up by the detector contains quantitative and qualitative information 
of the tested sample. Besides that, this technique has the features of high accuracy, fast response and in situ measurement and so on. And the reason why PGNAA provide information on the large measuring range is that both neutrons and gamma photos have a relatively long mean free path in tested materials. Through the principle analysis, the measured count rate A of a prompt gamma-rays from the capturing nuclide in the tested sample at $E_{\gamma}$ energy is given in Eq. 1 as follows [11]:

$$
A=\frac{\omega}{M} N_{A} \alpha \phi \sigma \lambda\left(E_{\gamma}\right) \varepsilon\left(E_{\gamma}\right)
$$

where $\omega$ and $M$, respectively, the mass and atomic mass of the element; $\mathrm{N}_{\mathrm{A}}$ is the Avogadro number and $\alpha$ is the isotopic abundance. $\lambda\left(E_{\gamma}\right)$ is the gamma-ray emission probability at the energy of $E_{\gamma} \varphi$ is the averaged thermal neutron flux throughout the whole volume sample. $\sigma$ is the capture cross section. $\varepsilon\left(E_{\gamma}\right)$ is the detection efficiency for the gamma-rays of energy $E_{\gamma}$.

In fact, it is not difficult to derive the element contents of hydrogen and other elements in landfill by PGNAA technique. When the moisture content changes, there is a certain available relationship between the characteristic prompt gamma-ray peak count of Hydrogen and moisture content. The moisture content can be directly deduced from the element contents of Hydrogen.

\section{Materials and Device}

Landfill Sample. In landfills, MSW has complex composition and commonly contains plastic, building waste, kitchen waste and other matter. And there's two parts of the MSW. While one part of it is water, another part is dry basis. Through research and investigation, the simplified element compositions of MSW dry basis in landfills are shown in Table 1 [12,13]. Typically, landfill bioreactor device reach moisture contents of 40-70\%.

Table 1. The simplified element compositions of MSW dry basis [\%]

\begin{tabular}{|c|c|c|c|c|c|}
\hline Element & $\mathrm{C}$ & $\mathrm{O}$ & $\mathrm{H}$ & $\mathrm{Si}$ & $\mathrm{Ca}$ \\
\hline Content & 25.65 & 44.8 & 3.15 & 20.9 & 5.5 \\
\hline
\end{tabular}

Due to the complexity of waste dry basis component, it is difficult to operate in sample preparation and filling when using municipal solid waste as the experimental subject. Besides, the moisture content of MSW is difficult to accurately control. Therefore, it is necessary to search for alternatives to MSW dry basis. The mixed substance with equal volume proportion of polyethylene and glass are similar to MSW dry basis in elementary composition and concentration. The element compositions of mixture are shown in Table 2. Because of the low neutron-absorption cross-section and relatively low concentration, the presence of sodium has little influence on result of a measurement. In addition, the grain size distribution of is dry basis mainly within the range of $8 \mathrm{~mm}$ to $25 \mathrm{~mm}{ }^{[14]}$, so the diameter of polyethylene balls and glass balls was set as $10 \mathrm{~mm}$. When interstitial place of mixture filled with deionized water, the moisture content is $59.8 \%$. As a consequence, the compounds of polyethylene balls, glass balls and deionized water were selected as the MSW alternatives for research.

Table 2. Comparision of the element compositions of alternatives to MSW dry basis [\%]

\begin{tabular}{|c|c|c|c|c|c|c|}
\hline Element & $\mathrm{C}$ & $\mathrm{O}$ & $\mathrm{H}$ & $\mathrm{Si}$ & $\mathrm{Ca}$ & $\mathrm{Na}$ \\
\hline Polyethylene & 85.71 & - & 14.29 & - & - & - \\
\hline $\begin{array}{c}\text { Glass } \\
\begin{array}{c}\text { MSW dry } \\
\text { basis }\end{array}\end{array}$ & - & 46.86 & - & 35.15 & 8.39 & 9.60 \\
\hline
\end{tabular}

Device design. According to the above-mentioned discuss, a new set-up with a ${ }^{241} \mathrm{Am}$-Be neutron source and a $4 \times 4$ inch $\mathrm{BGO}$ detector was proposed to make the study of moisture content measurement research in landfills, schematic diagram of set-up as shown in Fig. 1. The neutron source which located in the center of the whole setup was placed in a cylindrical container. A BGO detector is used to record prompt gamma spectra. It was just above the source, and separated by a block with $10 \mathrm{~cm}$ thickness mixture of polyethylene and $\mathrm{Li}_{2} \mathrm{CO}_{3}$ to reduce the neutron damage in the 
detector. The detector and the MSW sample are separated by sealed tube to avoid direct contact with each other with a diameter of $16 \mathrm{~cm}$. The setup was established by using Monte Carlo simulation.

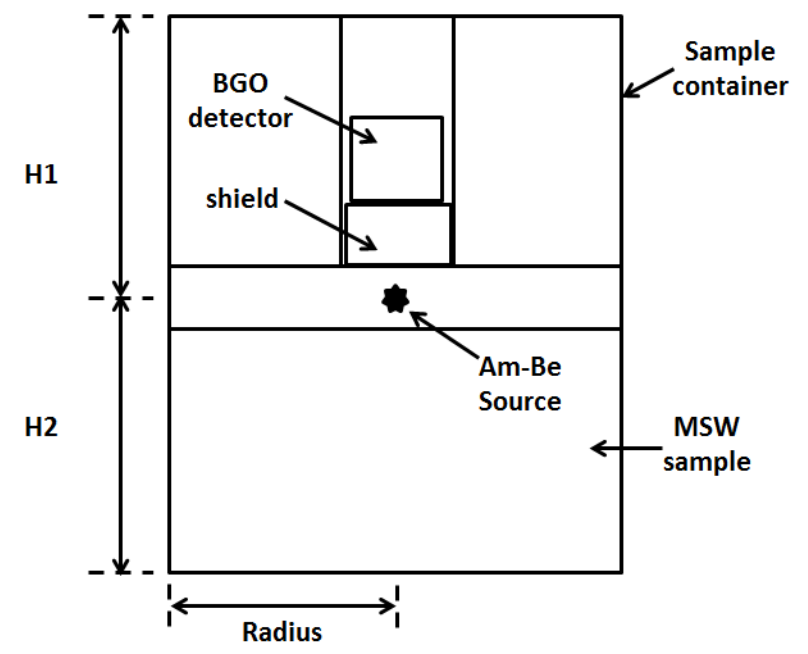

Fig. 1 Schematic diagram of the set-up for moisture content measurement in landfills

The suitable structure can increase the efficiency and reduce the measuring time of the elements detection. To identify the effectively detecting range and optimal geometric structure of setup, the outer radius and the height of detecting setup were changed by using the MCNP 4B code. Subsequently, the full energy peak counts of hydrogen at the energy of $2.223 \mathrm{MeV}$ were used to verify the results.

When using the alternatives as study subject which were listed in the Table 2, the simulation results for different outer radius of the MSW sample with $100 \mathrm{~cm}$ fixed height are shown in Fig. 2. The full energy peak counts of hydrogen shot up with the increase of outer radius when below thirty centimeters. Because the added parts of MSW sample increase the number of hydrogen that would make a greater contribution to the count of hydrogen peak. When the outer radius is higher than thirty centimeters, the count of hydrogen peak starts to saturate. Because the main neutron capture reaction is occurred within thirty centimeters. Furthermore, the distance would affect the counts of gamma-rays. So the outer radius is chosen to be thirty centimeters.

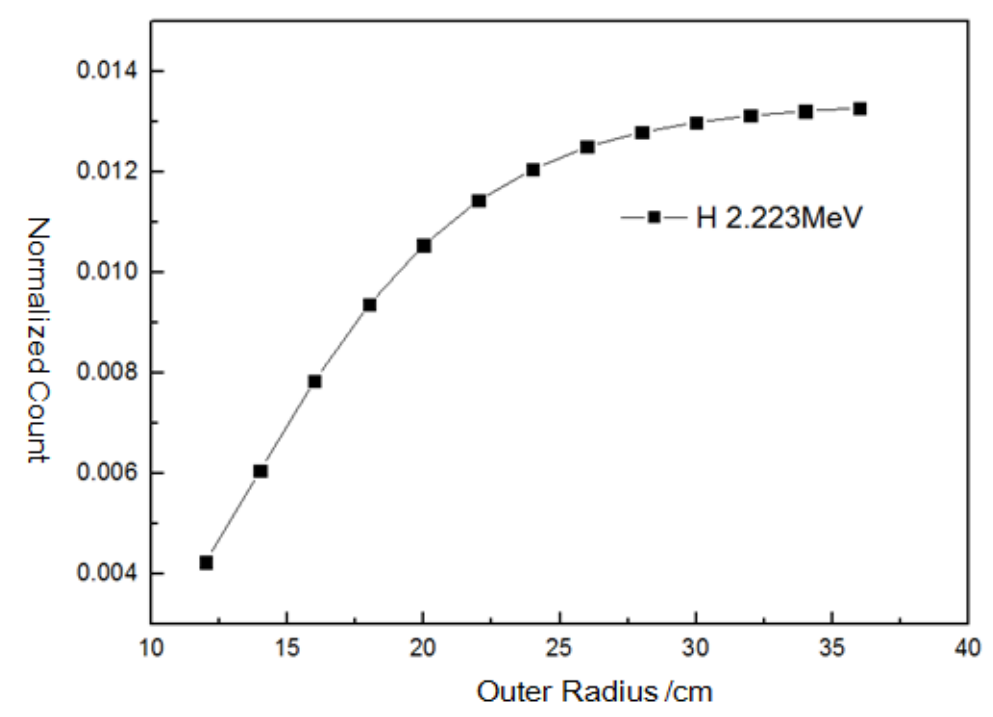

Fig. 2 Simulation results for outer radius of the sample

Similarly, the simulation results for different height of the MSW sample with $30 \mathrm{~cm}$ fixed outer radius are shown in Fig. 3 and Fig. 4 corresponding to the $\mathrm{H} 1$ and $\mathrm{H} 2$ respectively, as shown in Fig. 1. From Fig. 3 and Fig. 4 the best value of $\mathrm{H} 1$ and $\mathrm{H} 2$ can be determined to be both thirty centimeters. Hence, the total height of setup was chosen to be sixty centimeters. 


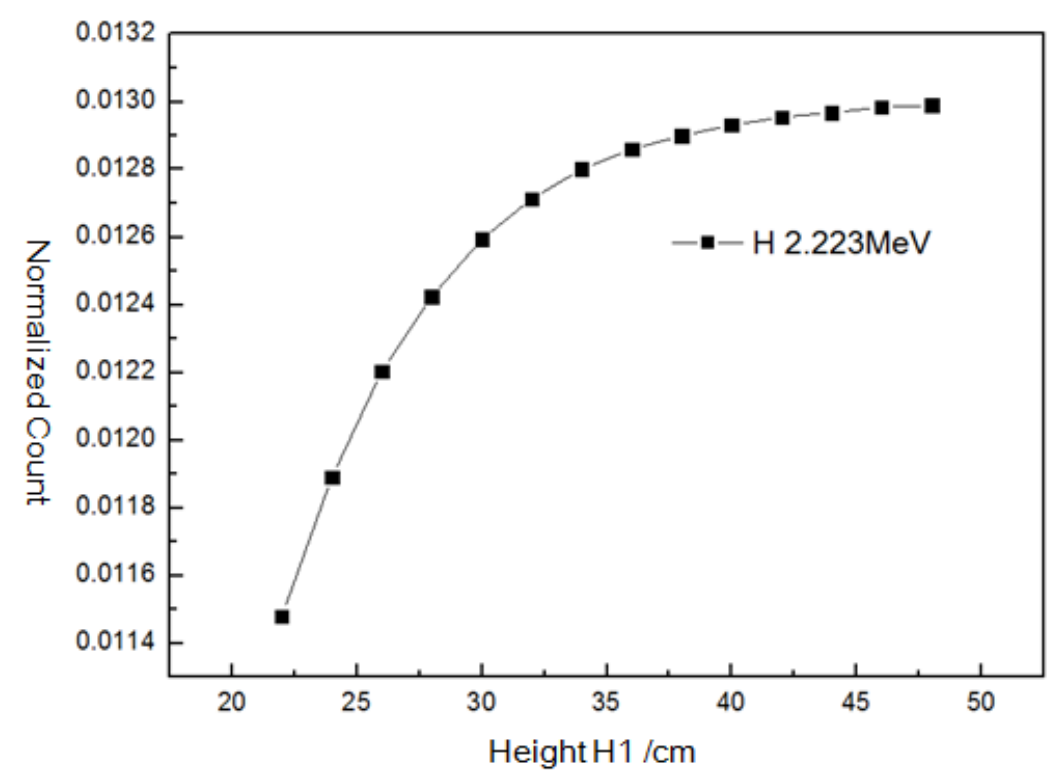

Fig. 3 Simulation results for the top half height $(\mathrm{H} 1)$ of the sample

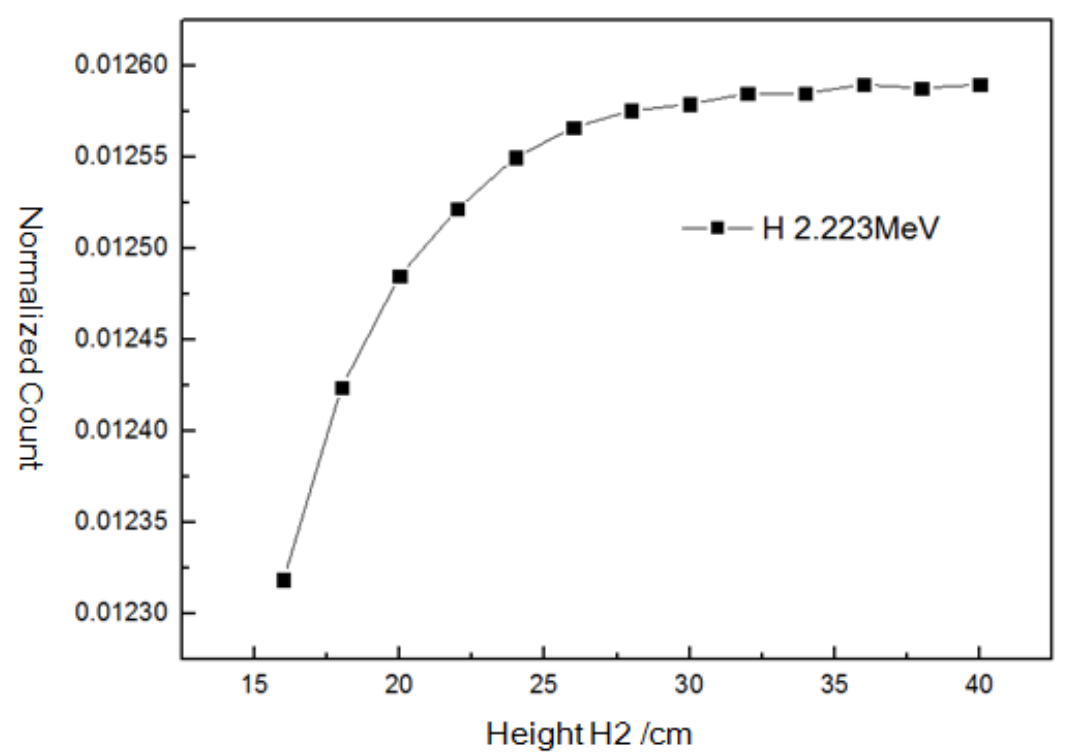

Fig. 4 Simulation results for the top half height $(\mathrm{H} 2)$ of the sample

\section{Moisture Contents Measurement}

Simulation. As the above-mentioned, the calculation model in MCNP code system was set up according to the three-dimensional geometrical modeling and the optimized size. The compounds of polyethylene balls, glass balls and deionized water were selected as the MSW alternatives for research. Nevertheless, the characteristic peak counts of hydrogen in gamma spectrum result from both the hydrogen in water and non-water bound hydrogen in dry basis. Some of the hydrogen from polyethylene balls can be treated as hydrogen in water, and then it is possible to regulate the water content by means of changing the proportion of polyethylene balls and glass balls. The relevant information of samples is listed in Table 3. The moisture contents of samples are set as 39.26\%, $46.307 \%, 53.899 \%, 62.102 \%, 70.991 \%$. And then five samples were used to simulate. MCNP was run until generated $1 \times 10^{9}$ histories on neutrons mode. The energy distribution of pulses created in the BGO detector was recorded by F4 tally. 
Table 3. The ratio and water content of alternatives to MSW

\begin{tabular}{|c|c|c|c|c|c|c|c|c|c|}
\hline \multirow{2}{*}{ Group } & \multirow{2}{*}{$\begin{array}{c}\text { Polyethylene } \\
\text { ratio [\%] }\end{array}$} & Glass & Watio & Water & \multicolumn{6}{|c|}{ Elements mass per unit volume [g] } \\
\cline { 6 - 11 } & {$[\%]$} & {$[\%]$} & $\mathrm{C}$ & $\mathrm{O}$ & $\mathrm{H}$ & $\mathrm{Si}$ & $\mathrm{Ca}$ & $\mathrm{Na}$ \\
\hline 1 & 44 & 56 & 39.260 & 0.095 & 0.170 & 0.788 & 0.062 & 0.227 & 0.054 \\
\hline 2 & 37.5 & 62.5 & 46.307 & 0.100 & 0.145 & 0.810 & 0.053 & 0.194 & 0.046 \\
\hline 3 & 31 & 69 & 53.899 & 0.105 & 0.120 & 0.832 & 0.044 & 0.160 & 0.038 \\
\hline 4 & 24.5 & 75.5 & 62.102 & 0.110 & 0.095 & 0.853 & 0.035 & 0.127 & 0.030 \\
\hline 5 & 18 & 82 & 70.991 & 0.115 & 0.070 & 0.875 & 0.025 & 0.093 & 0.022 \\
\hline
\end{tabular}

The simulation results of the count of hydrogen peak (2.223MeV) are shown in Fig. 5. A rising trend of the count of hydrogen peak can be observed with the increase of the moisture content. Using the least square method, the relationship between hydrogen peak and moisture content was studied and the results are shown in Fig. 6. The good linearity can also be figured out between the count of hydrogen peak and moisture content. The linear correlation coefficient is higher than 0.999 .

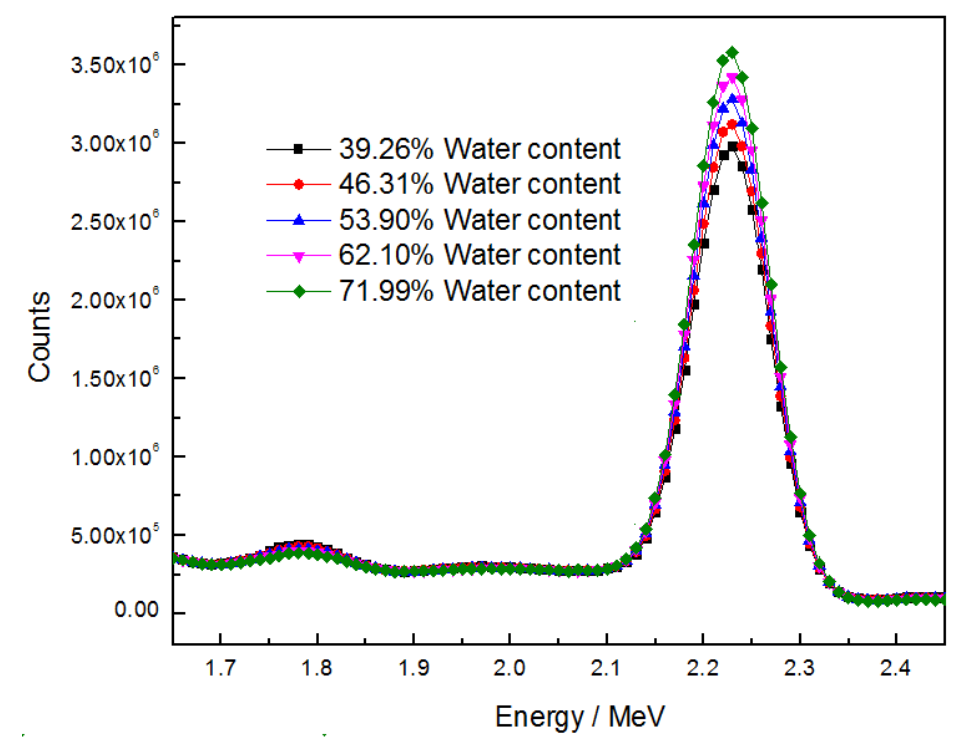

Fig. 5 MCNP simulation results for enlarged prompt $\gamma$-ray pulse height spectra of hydrogen peak

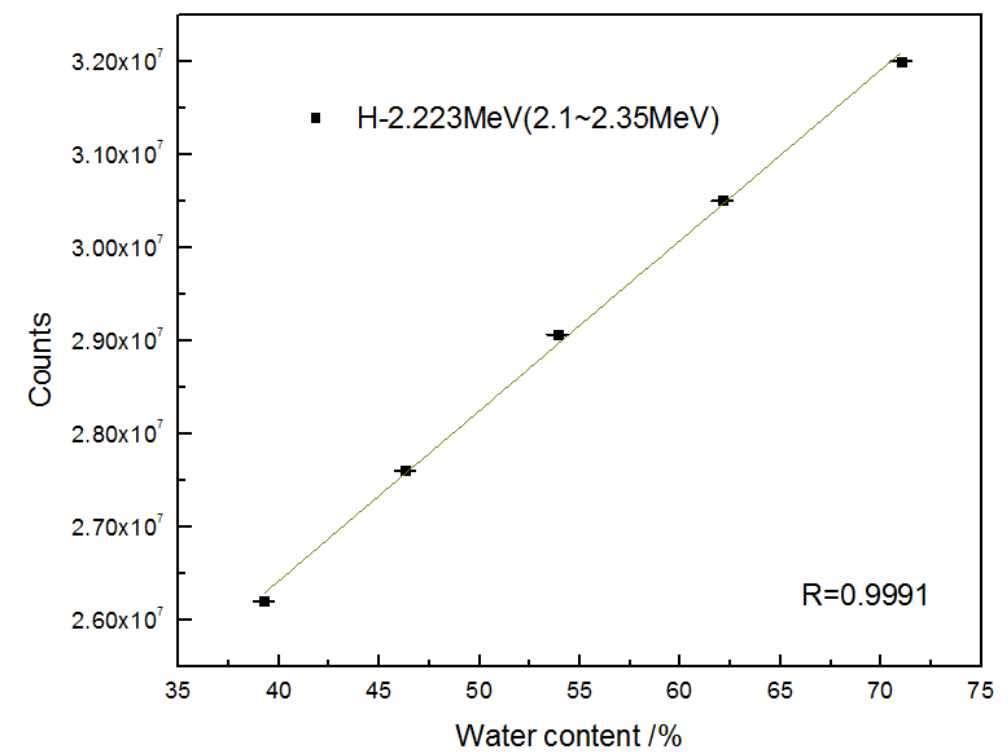

Fig. 6 MCNP simulation results for liner relationship between hydrogen peak and moisture content 
Experimental. The experimental setup was processed and assembled according to the optimized size and geometrical modeling, as shown in Fig. 7. The cylindrical container and sealed tube are made up of stainless steel material with a thickness of $2 \mathrm{~mm}$, while the PE pipes were used to inject deionized water. A $300 \mathrm{mCi}^{241} \mathrm{Am}-\mathrm{Be}$ neutron source, a $4 \times 4$ inch BGO detector (produced by Saint-Gobain), a digibase multi-channel analyzer (produced by ORTEC), MAESTRO-32 MCA Emulation Software (produced by ORTEC) were used in this experiment.

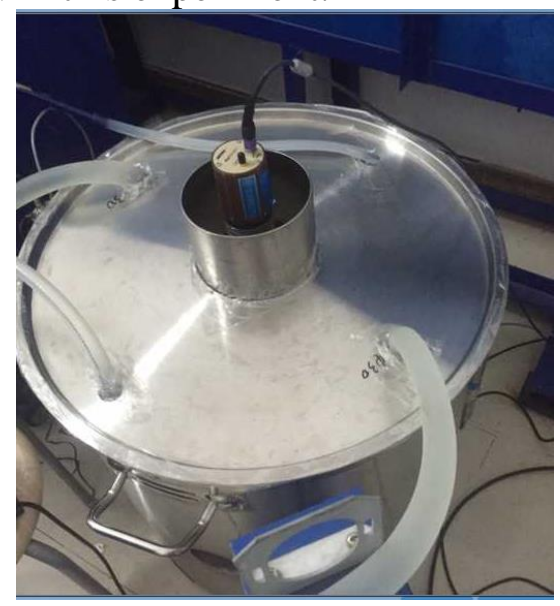

Fig. 7 Physical device of the PGNAA setup in this work

As shown in Table 3, the water content can be regulated by means of changing the proportion of polyethylene and glass ball. The relevant information of experimental samples is listed in Table 4 . The moisture contents of samples are set as $40.522 \%, 47.575 \%, 55.168 \%, 63.369 \%, 72.251 \%$. And then five samples were used to experimental measurement. The measuring live time of each sample was set to $3600 \mathrm{~s}$.

Table 4. The ratio and water content of alternatives to MSW in experiment

\begin{tabular}{|c|c|c|c|c|c|c|c|c|c|}
\hline \multirow{2}{*}{ Group } & \multirow{2}{*}{$\begin{array}{l}\text { Polyethylene } \\
\text { ratio [\%] }\end{array}$} & \multirow{2}{*}{$\begin{array}{c}\text { Glass } \\
\text { ratio } \\
{[\%]}\end{array}$} & \multirow{2}{*}{$\begin{array}{c}\text { Water } \\
\text { content } \\
{[\%]}\end{array}$} & \multicolumn{6}{|c|}{ Elements mass per unit volume [g] } \\
\hline & & & & $\mathrm{C}$ & $\mathrm{O}$ & $\mathrm{H}$ & $\mathrm{Si}$ & $\mathrm{Ca}$ & $\mathrm{Na}$ \\
\hline 1 & 40 & 60 & 40.522 & 0.090 & 0.247 & 0.685 & 0.061 & 0.222 & 0.053 \\
\hline 2 & 34 & 66 & 47.575 & 0.094 & 0.272 & 0.641 & 0.052 & 0.189 & 0.045 \\
\hline 3 & 28 & 72 & 55.169 & 0.098 & 0.297 & 0.596 & 0.043 & 0.155 & 0.037 \\
\hline 4 & 22 & 78 & 63.369 & 0.102 & 0.322 & 0.552 & 0.033 & 0.122 & 0.029 \\
\hline 5 & 16 & 84 & 72.251 & 0.106 & 0.346 & 0.507 & 0.024 & 0.089 & 0.021 \\
\hline
\end{tabular}

The experimental results of the count of hydrogen peak $(2.223 \mathrm{MeV})$ are shown in Fig. 8. A rising trend of the count of hydrogen peak can also be observed with the increase of the moisture content. The relationship between hydrogen peak and moisture content was studied and the results are shown in Fig. 9. The good linearity can also be figured out between the count of hydrogen peak and moisture content. The linear correlation coefficient is higher than 0.99 . 


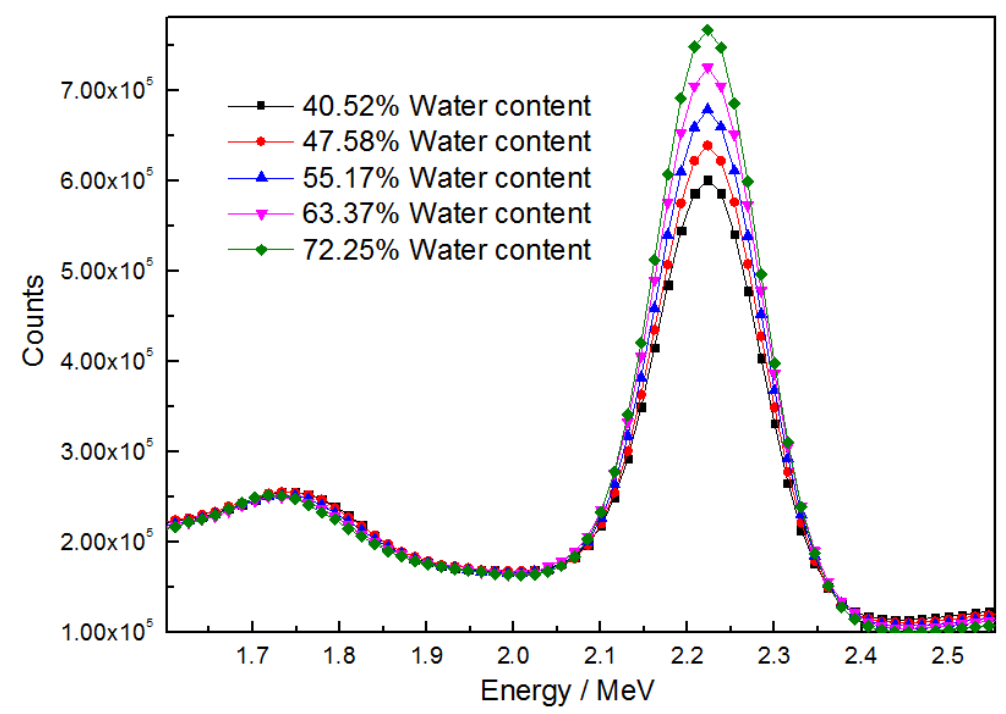

Fig. 8 Enlarged prompt $\gamma$-ray experimental pulse height spectra of hydrogen peak

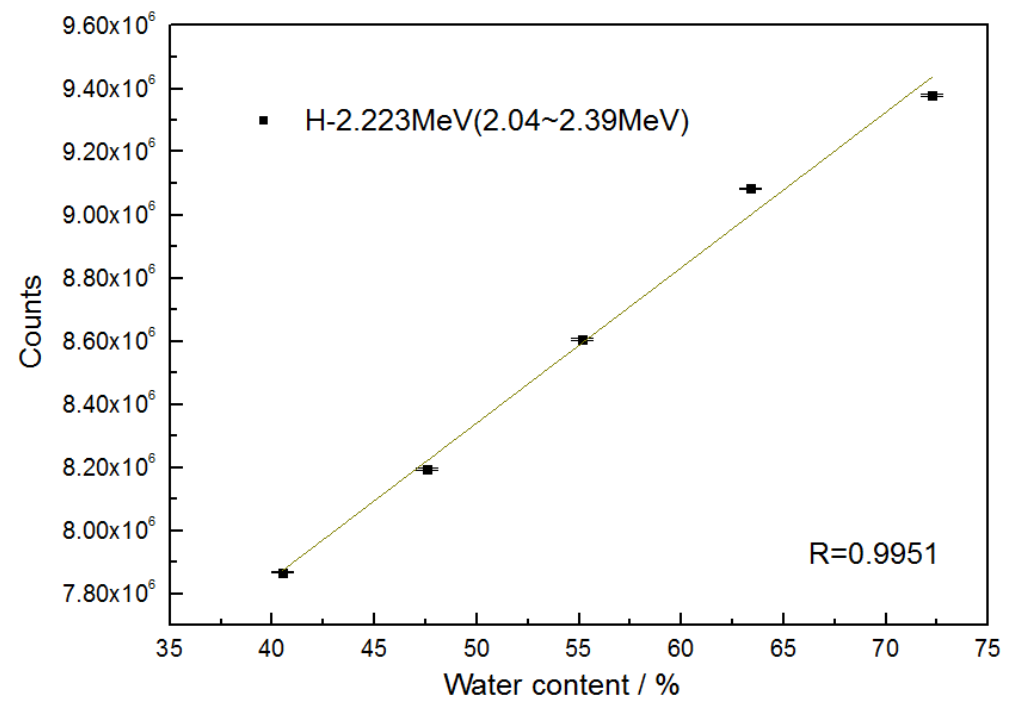

Fig. 9 Liner relationship between hydrogen peak counts and moisture content

\section{Estimation of Moisture Content}

Landfills containing a certain amount of element calcium that mainly exist in the glass, brick, stone and inorganic minerals, and calcium content in the waste dry base is relatively stable. It can be used as the internal mono-standard. As shown as Eq. 2, the ratio of the full energy peak areas $\left(A_{\mathrm{H}} / A_{\mathrm{Ca}}\right)$ from an isotope of the element hydrogen to that of the element calcium is related to weight ratio $(\omega \mathrm{H} / \omega \mathrm{Ca})$.

$$
\frac{A_{H}}{A_{C a}}=\frac{\omega_{H} N_{\mathrm{A}} \alpha_{H} \phi \sigma_{H} \lambda_{H} \varepsilon_{H}}{\omega_{C a} N_{\mathrm{A}} \alpha_{C a} \phi \sigma_{C a} \lambda_{C a} \varepsilon_{C a}} \cdot \frac{M_{C a}}{M_{H}}=\frac{\omega_{H}}{\omega_{C a}} \cdot k_{0, H}(\mathrm{Ca}) \cdot \frac{\varepsilon_{H}}{\varepsilon_{C a}}
$$

Where $\varepsilon$ is the gamma-ray detection efficiency, and $k_{0, \mathrm{H}}(\mathrm{Ca})$ is the relative analytical sensitivity factor of element calcium respect to element hydrogen. In this research, the numerical value of $k_{0, \mathrm{H}}(\mathrm{Ca}) \cdot \varepsilon \mathrm{H} / \varepsilon \mathrm{Ca}$ is fixed. By analyzing the simulated data, element weight ratio $(\omega \mathrm{H} / \omega \mathrm{Ca})$ estimated value are listed in Table 5.

Table 5. Element weight ratio estimated value

\begin{tabular}{|c|c|c|c|}
\hline Group & Water content $[\%]$ & $A_{\mathrm{H}} / A_{\mathrm{Ca}}$ & $\omega_{\mathrm{H}} / \omega_{\mathrm{Ca}}$ \\
\hline 1 & 38.2 & 37.733 & 1.755 \\
\hline 2 & 45.5 & 46.362 & 2.167 \\
\hline 3 & 53.3 & 60.203 & 2.753 \\
\hline 4 & 61.8 & 80.697 & 3.649 \\
\hline 5 & 71.0 & 120.632 & 5.192 \\
\hline
\end{tabular}


Research found that hydrogen content in dry basis change within the same area is small [15]. Therefore assume that hydrogen and calcium content ratio $\left(\omega \mathrm{Ho} / \omega_{\mathrm{Ca}}\right)$ in the dry basis is determined, and the calcium content $\left(\mu_{\mathrm{Ca}}\right)$ remains constant. Combining with the $\mathrm{k}_{0}$ method can obtain mass ratio of hydrogen and calcium $(\omega \mathrm{H} / \omega \mathrm{Ca})$. Thus the mass ratio of hydrogen in water and calcium in dry basis $\left(\omega_{\mathrm{H} 1} / \omega_{\mathrm{Ca}}\right)$ can be calculated. The formula which can be used to estimate the moisture content is given in Eq. 3. As shown in Table 6, the mean absolute error is about $1.84 \%$.

$$
\eta=\frac{\omega_{\mathrm{H}_{2} \mathrm{O}}}{\omega_{\mathrm{ISW}}}=\frac{\omega_{\mathrm{H}_{2} \mathrm{O}}}{\omega_{\mathrm{H}_{2} \mathrm{O}}+\omega_{\text {dry basis }}}=\frac{9 \omega_{\mathrm{H} 1}}{9 \omega_{\mathrm{H} 1}+\omega_{\mathrm{Ca}} / \mu_{\mathrm{Ca}}}=\frac{9}{9+1 /\left(\mu_{\mathrm{Ca}} \cdot\left(\omega_{H} / \omega_{C a}-\omega_{\mathrm{HO}} / \omega_{C a}\right)\right)}
$$

Table 6. The moisture content estimated results

\begin{tabular}{|c|c|c|}
\hline $\begin{array}{c}\text { The set value of the moisture } \\
\text { content [\%] }\end{array}$ & $\begin{array}{c}\text { The calculated value of the } \\
\text { moisture content [\%] }\end{array}$ & Absolute error[\%] \\
\hline 39.26 & 40.73 & 1.47 \\
\hline 46.31 & 47.72 & 1.42 \\
\hline 53.90 & 56.04 & 2.15 \\
\hline 62.10 & 64.43 & 2.33 \\
\hline 70.99 & 74.07 & 3.08 \\
\hline
\end{tabular}

\section{Conclusion}

A set-up which consist of a ${ }^{241} \mathrm{Am}-\mathrm{Be}$ neutron source and a $4 \times 4$ inch BGO detector was proposed for moisture and chlorine content determination in landfills. The results show that the count of hydrogen peak increase with the increase of the moisture content for samples, and good linearity can be figured out between the counts of hydrogen peak and moisture content. Experimental results and simulation results are in good conformity with the linear correlation coefficients are higher than 0.99 . Using $\mathrm{k}_{0}$ method for moisture content estimation, the mean absolute error is about $1.84 \%$.

\section{Acknowledgements}

This work was supported by the National Natural Science Foundation of China (Grant No. 11405086) and National Key Scientific Instrument and Equipment Development Projects (Grant No. 2013YQ040861). And this work was supported by a Project Funded by the Priority Academic Program Development of Jiangsu Higher Education Institutions (PAPD).

\section{References}

[1] G. Tchobanoglous, H. Theisen, S. Vivil. Integrated Solid Waste Management: Engineering Principles and Management Issues. McGraw-Hill Inc., New York, 1993 Chapter 11.

[2] D. Reinhart, P. Mc Creanor, T. Townsend: Waste Manage. Res., 2002(20): 172-186.

[3] R. Mehta, M. A. Barlaz, R. Yazdani , et al. : J. Environ. Eng., 2002(128): 228-236.

[4] M.A. Barlaz, C.A. Bareither, A. Hossain, et al.: J. Geotech. Geoenviron. Eng, 2010(136): 839-853.

[5] C.A. Bareither, C. H. Benson, M. A. Barlaz, et al.: Environ. Eng, 2010(136): 24-38.

[6] S. T. S. Yuen, T. A. McMahon, J. R. Styles: Journal of Environmental Engineering, 2000, 126 (12): 1088-1095.

[7] N. A. Gawande, D. Reinhart, P. A. Thomas, et al.: Waste Management, 2003(23): 667-674.

[8] P. T. Imhoff, A. Jakubowitch, M. L. Briening, et al.: Journal of the Air \&Waste Management Association, 2003(53):1-10. 
[9] P. T. Imhoff, D. Reinhart, M. Englund , et al.: Waste Management, 2007, 27(6):729-745

[10] A. Favalli, H. C. Mehner, V. Ciriello, et al.: Appl. Radiat. Isotopes, 2010, 68: 901-904.

[11]Z. Idiri, H. Mazrou, A. Amokrane, et al.: Nuclear Instruments and Methods in Physics Research Section B: Beam Interactions with Materials and Atoms, 2010, 268(2): 213-218.

[12]Q. C. Qian: Environmental Sanitation Engineering, 2009, 17(4): 15-19 (in chinese).

[13] Y. Y. Xi, H. J. Li, W. B. Fan, et al.: Shanghai Environmental Sciences, 2002, 21(12): 721-724( in chinese).

[14]Y. Long, D. S. Shen, H. M. Lao, et al.: Acta Scientiae Circumstantiae, 2007, 27(9): 1485-1490( in chinese).

[15]Y. Y. Xi, H. J. Li, W. B. Fan: Shanghai Environmental Sciences, 2002, 21(12): 721-724( in chinese) . 